\title{
Distinct Roles for Different Homer1 Isoforms in Behaviors and Associated Prefrontal Cortex Function
}

\author{
Kevin D. Lominac, ${ }^{1}$ Erik B. Oleson, ${ }^{1}$ Matthew Pava, ${ }^{1}$ Matthias Klugmann, ${ }^{2}$ Martin K. Schwarz, ${ }^{3}$ Peter H. Seeburg, ${ }^{3}$ \\ Matthew J. During, ${ }^{2}$ Paul F. Worley, ${ }^{4}$ Peter W. Kalivas, ${ }^{1}$ and Karen K. Szumlinski ${ }^{1}$ \\ ${ }^{1}$ Department of Neurosciences, Medical University of South Carolina, Charleston, South Carolina 29425, ${ }^{2}$ Department of Molecular Medicine and \\ Pathology, University of Auckland, Auckland 1003, New Zealand, ${ }^{3}$ Department of Molecular Neurobiology, Max Planck Institute Medical Research, 69120 \\ Heidelberg, Germany, and ${ }^{4}$ Department of Neuroscience, The Johns Hopkins University School of Medicine, Baltimore, Maryland 21205
}

Homer1 mutant mice exhibit behavioral and neurochemical abnormalities that are consistent with an animal model of schizophrenia. Because the Homerl gene encodes both immediate early gene (IEG) and constitutively expressed (CC) gene products, we used the local infusion of adeno-associated viral vectors carrying different Homer1 transcriptional variants into the prefrontal cortex (PFC) to distinguish between the roles for IEG and CC Homer1 isoforms in the "schizophrenia-like" phenotype of Homer1 mutant mice. PFC overexpression of the IEG Homerl isoform Homerla reversed the genotypic differences in behavioral adaptation to repeated stress, whereas overexpression of the constitutively expressed Homer 1 isoform Homer 1c reversed the genotypic differences in sensorimotor and cognitive processing, as well as cocaine behavioral sensitivity. Homerla overexpression did not influence PFC basal glutamate content but blunted the glutamate response to cocaine in wild-type mice. In contrast, Homer1c overexpression reversed the genotypic difference in PFC basal glutamate content and enhanced cocaine-induced elevations in glutamate. These data demonstrate active and distinct roles for Homerla and Homer 1c isoforms in the PFC in the mediation of behavior, in the maintenance of basal extracellular glutamate, and in the regulation of PFC glutamate release relevant to schizophrenia and stimulant abuse comorbidity.

Key words: cocaine; knock-out; Homer proteins; prefrontal cortex; glutamate; schizophrenia

\section{Introduction}

Abnormalities in frontal cortical glutamate are implicated in the pathophysiology of schizophrenia (Tsai and Coyle, 2002; Krystal et al., 2003). Linkage analyses identified a single nucleotide polymorphism in the intronic sequence of Homer1 (IVS4 + 18A > G) associated with this disorder (Norton et al., 2003). Constitutively expressed forms of Homer1 (Homer1b, Homer1c, Homer1d) contain an N-terminal Ena/VASP1 Homology (EVH1) domain and a C-terminal coiled-coil (CC) domain and function to: (1) increase group 1 metabotropic glutamate receptor (mGluR) coupling to inositol triphosphate and ryanodine receptors (Ango et al., 2001; Fagni et al., 2002; Feng et al., 2002) and to phosphatidyl inositol 3 kinase (Rong et al., 2003); (2) regulate cation influx through transient receptor potential channels (Yuan et al., 2003)

Received Sept. 6, 2005; revised Nov. 2, 2005; accepted Nov. 3, 2005.

This work was supported in part by United States Public Health Service Grants DA-11742 and DA-10307 (P.F.W.) and DA-03906, DA-14185, and MH-40817 (P.W.K.) and a National Alliance for Research on Schizophrenia and Depression Young Investigator Award to K.K.S. We thank Stephen Welt for his technical assistance, Joe Vallone for genotyping and maintenance of the mouse colony, and Shin Kang and Marlin Dehoff for generating the KO mice and assays for genotyping.

Correspondence should be addressed to Dr. Karen K. Szumlinski, Department of Psychology, University of California, Santa Barbara, Santa Barbara, CA 93106-9660. E-mail: szumlinski@psych.ucsb.edu.

K. D. Lominac's present address: Department of Psychology, University of California, Santa Barbara, Santa Barbara, CA 93106-9660.

M. Klugmann's present address: Department of Neurobiology, Interdisciplinary Center for Neurosciences, University of Heidelberg, Im Neuenheimer Feld 364, D-69129 Heidelberg, Germany.

D0I:10.1523/JNEUROSCI.3764-05.2005

Copyright $\odot 2005$ Society for Neuroscience $\quad$ 0270-6474/05/2511586-09\$15.00/0 and $\mathrm{N}$-type calcium and M-type potassium channels (Kammermeier et al., 2000); and (3) cross-link other proteins associated with the NMDA subtype of ionotropic glutamate receptors (Naisbitt et al., 1999; Tu et al., 1999) to promote efficient excitatory signaling complexes (Xiao et al., 2000; Fagni et al., 2002). In contrast to constitutively expressed Homer proteins (CCHomers), ania-3 and Homerla are Homer 1 transcriptional variants that exhibit an immediate early gene (IEG) profile of expression after synaptic activation (Brakeman et al., 1997; Kato et al., 1998; Bottai et al., 2002). IEG Homer1 isoforms possess the EVH1 domain but lack the CC motif required for HomerHomer multimerization (Bottai et al., 2002). IEG Homers thereby function as natural dominant negatives that disrupt CCHomer interactions with EVH1-bound proteins (Xiao et al., 2000; Fagni et al., 2002), resulting in a modification of synaptic architecture (Sala et al., 2001; 2003), redistribution of CC-Homer expression (Inoue et al., 2004), and an alteration in excitatory synaptic transmission (Abe et al., 2003; Hennou et al., 2003; Minami et al., 2003).

Homer1 knock-out (KO) mice exhibit a "schizophrenia-like" behavioral phenotype characterized by heightened anxiety and "behavioral despair," impaired sensorimotor, cognitive, and motivational processing as well as increased behavioral sensitivity to both psychomotor stimulant and dissociative anesthetic drugs (Szumlinski et al., 2004, 2005a). Moreover, acute administration of the typical antipsychotic haloperidol completely reverses the genotypic differences in sensorimotor function (Szumlinski et 
al., 2005a). Homer1 KO mice exhibit an 50\% increase in basal extracellular levels of prefrontal cortex (PFC) glutamate and a reduced capacity of cocaine to elevate PFC glutamate levels, suggesting hypo-frontality (Szumlinski et al., 2005a). Because Homer1 gene deletion eliminates both IEG and CC-Homer products, we infused adeno-associated viral vectors (AAVs) carrying either Homer $1 a$ or Homer $1 c$ into the PFC to address the relative role for these different Homer1 isoforms in the "schizophrenia-like" behavioral and neurochemical phenotype of Homer1 KO mice. Because AAV-mediated upregulation of Homerlc, but not Homerla, reverses the expression of behavioral and glutamate sensitization in a cocaine-sensitized animal model of psychosis (Szumlinski et al., 2005c), it was hypothesized that the PFC upregulation of Homer $1 \mathrm{c}$ would reverse the differences in cognitive, sensorimotor, and emotional processing as well as cocaine sensitivity observed between Homer 1 wild-type (WT) and KO mice. The present results confirm active, but distinct, roles for PFC Homerla and Homer1c expression in contributing to the behavioral phenotype of Homer1 KO mice and implicate the modulation of PFC basal and evoked glutamate transmission by Homer1c in normal cognitive and sensorimotor function. Moreover, these data implicate Homer-associated intracellular signaling mechanisms as potential targets for the development of novel pharmacotherapeutics for the treatment of psychotic disorders.

\section{Materials and Methods}

Animals. Subjects were WT and Homer1 KO mice [cytomegalovirus $(\mathrm{CMV})-\mathrm{Cre}(\mathrm{BALB} / \mathrm{cJ}) \times$ Flpe $(\mathrm{C} 57 \mathrm{BL} / 6 \times 129 \mathrm{sv}) \times \mathrm{C} 57 \mathrm{BL} / 6]($ Szumlinski et al., 2004, 2005a). Mice were housed individually in an Association for Assessment and Accreditation of Laboratory Animal Careapproved animal facility in standard mouse cages (lights on at 8:00 A.M.; $25^{\circ} \mathrm{C}$; food and water available ad libitum). All testing was conducted during the light cycle. All experiments were approved by the Institutional Animal Care and Use Committee of the Medical University of South Carolina and conducted in accordance with the National Institutes of Health Principles of Laboratory Animal Care. Because insufficient numbers of one gender were available at the time of study, both male and female mice were used. As per our previous results, no gender differences were observed for any of the variables examined (no main effects of, or interactions with, the gender factor; $p>0.05$ ).

Construction of $A A V$. Because Homerlc is the predominant CCHomer isoform in rodents, the rat Homerla and Homer1c coding sequences were amplified using whole-brain cDNA, and the PCR was product expressed as an $\mathrm{N}$-terminal fusion protein with the hemagglutinin (HA)-tag in a rAAV backbone containing the $1.1 \mathrm{~kb}$ CMV enhancer/ chicken-actin (CBA) promoter, 800 bp human interferon scaffold attachment region inserted 5_ of the promoter, the woodchuck posttranscriptional regulatory element (WPRE), and the bovine growth hormone polyA flanked by inverted terminal repeats (AAV-Homerla, AAV-Homerlc). The same AAV-CBA-WPRE-bGH backbone encoding the enhanced green fluorescent protein (EGFP) was used as control (AAV-GFP). AAV pseudotyped vectors (virions containing a 1:1 ratio of AAV1 and AAV2 capsid proteins with AAV2 intertrigeminal regions were generated as described previously (Hauck et al., 2003). Briefly, human embryonic kidney 293 cells were transfected with the AAV cisplasmid, the AAV1 (pH21) and AAV2 (pRV1) helper plasmids (pF6), and the adenovirus helper plasmid by standard calcium phosphate transfection methods. Forty-eight hours after transfection, cells were harvested and the vector purified using heparin affinity columns as described previously (During et al., 2003). Genomic titers were determined using the Prism 7700 sequence detector system (Applied Biosystems, Foster City, CA) with primers designed to WPRE as described previously (Clark et al., 1999).

Surgical procedures and AAV infusion. Under pentobarbital anesthesia ( $50 \mathrm{mg} / \mathrm{kg}$, i.p.), naive mice (5-7 weeks of age) were implanted bilaterally with a 20 -gauge stainless steel guide cannula (20 mm long) aimed $3 \mathrm{~mm}$ above the prefrontal cortex (anteroposterior, $+1.34 \mathrm{~mm}$; mediolateral, $\pm 0.6 \mathrm{~mm}$; dorsoventral, $-2.0 \mathrm{~mm}$; relative to bregma), and the guide cannulas were fixed to the skull using dental resin as described previously (Szumlinski et al., 2004, 2005a,b). After at least $7 \mathrm{~d}$ of recovery, mice were infused bilaterally at a rate of $0.05 \mu \mathrm{l} / \mathrm{min}$ for $5 \mathrm{~min}$ (total volume, 0.25 $\mu \mathrm{l} /$ side) with either an AAV carrying the Homerla or the Homerlc transcriptional variant of the Homer1 gene or an AAV carrying EGFP as a control (Szumlinski et al., 2004, 2005b). Behavioral testing commenced at 3 weeks after infusion. AAV transfection and localization was verified by immunostaining for the HA tag as described previously (Szumlinski et al., 2004, 2005b,c; Klugmann et al., 2005).

Behavioral testing battery. AAV-infused mice were subjected to a battery of behavioral tests to delineate the relative contribution of Homerla and Homerlc to the abnormal behavioral phenotype of Homerl KO mice. Unless otherwise indicated, all tests were conducted similarly as described in our original characterization of the Homer1 KO phenotype (Szumlinski et al., 2005a). In all, five replicates of 12-18 animals were examined, the order of behavioral testing was varied slightly across replicates, and 4-5 d separated each behavioral test. Prepulse inhibition (PPI) was conducted toward the end of the third week after AAV infusion in a manner identical to that described in detail previously (Szumlinski et al., 2005a). Animals were then assessed for behavioral despair in a Porsolt swim test (one $15 \mathrm{~min}$ exposure, followed $24 \mathrm{~h}$ later by a $5 \mathrm{~min}$ test) or for working memory in a water version of the radial arm maze (14 d of training with four 2 min trials per day) (Szumlinski et al., 2005a). Animals were next assessed for locomotor activity in response to being placed into a novel activity monitor (30 min session) and then for the habituation of locomotor reactivity after four subsequent daily exposures. Consistent with a relatively high prevalence of comorbidity between schizophrenia and stimulant abuse disorders (Batel, 2000; Gerber and Tonegawa, 2004), Homer1 KO mice exhibit enhanced behavioral sensitivity to the rewarding and psychomotor-activating effects of cocaine (Szumlinski et al., 2004). Thus, the last behavioral experiment assessed cocaine-induced locomotion and used a repeated measures design in which all mice received one of four cocaine doses $(0,3,10$, and 30 $\mathrm{mg} / \mathrm{kg}$, i.p.; volume, $0.01 \mathrm{ml} / \mathrm{g}$ ) in a counterbalanced manner on tests separated by $2-3 \mathrm{~d}$. No habituation period proceeded the cocaine injection sessions, and mice were monitored for $60 \mathrm{~min}$ after injection.

In vivo microdialysis and HPLC procedures. No net-flux and conventional microdialysis were conducted as described previously (Szumlinski et al., 2004, 2005a,c). A within-subjects design was used in which mice were first tested using the no-flux technique and then conventional microdialysis was conducted $4-5 \mathrm{~d}$ later using the contralateral side of the head. For the no net-flux study, increasing concentrations of glutamate $(0,2.5,5$, and $10 \mu \mathrm{M})$ were infused through the probe for $1 \mathrm{~h}$ for each concentration. For the cocaine study, baseline samples were collected for $60 \mathrm{~min}$ before an intraperitoneal injection of $10 \mathrm{mg} / \mathrm{kg}$ cocaine (volume, $0.01 \mathrm{ml} / \mathrm{g}$ ) and then for $120 \mathrm{~min}$ thereafter. Glutamate in the dialysis sample was measured using an HPLC system with fluorescent detection in a manner identical to that described previously (Szumlinski et al., 2004, 2005a,b,c).

Statistical analyses. It was hypothesized that AAV-Homer1c infusion would selectively reverse the differences in behavior and PFC glutamate observed between Homer $1 \mathrm{WT}$ and $\mathrm{KO}$ mice, and thus all univariate data were analyzed using planned orthogonal comparisons between WT and KO mice within each AAV treatment (Glass and Hopkins, 1984). For data involving repeated measures (cocaine-induced locomotion and changes in extracellular glutamate), the data were analyzed using an analysis of variance. If significant interactions were found, the data were decomposed for main effects of genotype. Because multiple comparisons using one group were not conducted, $\alpha=0.05$ for all comparisons. The results of these analyses are presented in Table 1.

\section{Results}

Verification of PFC transfection by AAV

To delineate the roles for Homerla and Homerlc in the PFC phenotype of Homer1 $\mathrm{KO}$ mice, groups of WT and $\mathrm{KO}$ mice were bilaterally infused intra-PFC with AAVs carrying Homerla, Homer1c, or GFP control cDNA. Both Homerla and Homer1c 
Table 1. Summary of the results of planned comparisons between WT and KO mice within each AAV treatment group

\begin{tabular}{|c|c|c|c|c|}
\hline Paradigm & Dependent variable & GFP & Homer1a & Homer1c \\
\hline Radial arm maze & $\begin{array}{l}\text { Latency to navigate maze } \\
\text { Working memory errors } \\
\text { Chaining }\end{array}$ & $\begin{array}{l}F_{(1,17)}=5.10 ; p=0.04 \\
F_{(1,17)}=5.03 ; p=0.05 \\
F_{(1,17)}=11.49 ; p=0.003\end{array}$ & $\begin{array}{l}F_{(1,14)}=9.57 ; p=0.0008 \\
F_{(1,14)}=9.32 ; p=0.009 \\
F_{(1,14)}=6.44 ; p=0.02\end{array}$ & $\begin{array}{l}F_{(1,14)}=2.29 ; p=0.15 \\
F_{(1,14)}=2.08 ; p=0.17 \\
F_{(1,14)}=0.45 ; p=0.51\end{array}$ \\
\hline PPI & PPI by $90 \mathrm{~dB}$ & $F_{(1,20)}=4.51 ; p<0.0001$ & $F_{(1,14)}=2.17 ; p=0.04$ & $F_{(1,15)}=0.30 ; p=0.77$ \\
\hline Porsolt swim & $\begin{array}{l}\text { Latency to float } \\
\text { Amount of floating }\end{array}$ & $\begin{array}{l}F_{(1,19)}=3.21 ; p=0.05 \\
F_{(1,19)}=3.00 ; p=0.05\end{array}$ & $\begin{array}{l}F_{(1,17)}=0.85 ; p=0.37 \\
F_{(1,17)}=2.54 ; p=0.13\end{array}$ & $\begin{array}{l}F_{(1,18)}=12.15 ; p=0.003 \\
F_{(1,18)}=24.92 ; p<0.0001\end{array}$ \\
\hline Reactivity to novelty & Total distance in $30 \mathrm{~min}$ & $F_{(1,12)}=3.21 ; p=0.04$ & $F_{(1,10)}=0.86 ; p=0.38$ & $F_{(1,10)}=0.08 ; p=0.78$ \\
\hline Habituation & Change in total distance (sessions 5 to 1 ) & $F_{(1,12)}=6.17 ; p=0.03$ & $F_{(1,10)}=0.10 ; p=0.76$ & $F_{(1,10)}=12.16 ; p=0.006$ \\
\hline Cocaine-induced locomotion ( $0-30 \mathrm{mg} / \mathrm{kg}$, i.p.) & Total distance in $120 \mathrm{~min}$ & $F_{(1,15)}=3.85 ; p=0.05$ & $F_{(1,16)}=5.41 ; p=0.03$ & $F_{(1,12)}=1.14 ; p=0.31$ \\
\hline Saline-induced locomotion & Total distance in $120 \mathrm{~min}$ & $F_{(1,15)}=4.06 ; p=0.05$ & $F_{(1,16)}=1.55 ; p=0.23$ & $F_{(1,12)}=4.02 ; p=0.05$ \\
\hline No net-flux microdialysis & Basal glutamate concentration $(y=0)$ & $F_{(1,13)}=5.85 ; p=0.03$ & $F_{(1,16)}=3.92 ; p=0.05$ & $F_{(1,11)}=0.42 ; p=0.53$ \\
\hline Cocaine-induced rise in glutamate & Time course of extracellular glutamate levels & $F_{(1,12)}=3.58 ; p=0.05$ & $F_{(1,13)}=0.74 ; p=0.41$ & $F_{(1,13)}=1.63 ; p=0.26$ \\
\hline
\end{tabular}

were HA-tagged, and AAV transfection was verified by immunostaining after completion of experimentation (at 8-10 weeks after infusion) (Fig. 1a,b). In both cases, cellular transfection was restricted to an area of $\sim 1-1.5 \mathrm{~mm}$ around the injection/probe site, which was located in the dorsal PFC, and Homer protein expression was localized to both processes and soma of pyramidal neurons (Fig. 1a', $b^{\prime}$ ).

$A A V$-GFP infusion does not alter the behavioral or neurochemical abnormalities produced by Homer1 deletion

Compared with WT mice, Homer1 KO mice exhibit abnormalities in working memory, sensorimotor gating, and emotional reactivity that are associated with increased basal extracellular levels of glutamate in the PFC as well as a reduction in stimulated glutamate release in this brain region (Szumlinski et al., 2005a). Consistent with the results of our previous report, similar differences in behavior and PFC extracellular levels of glutamate were observed between WT and $\mathrm{KO}$ mice infused intra-PFC with AAV-GFP control (Table 1). KO control mice exhibited the following: (1) impairments in the acquisition of a radial arm maze and deficits in prepulse inhibition of acoustic startle (Fig. 2); (2) increased behavioral despair in a Porsolt swim test as well as heightened behavioral reactivity to a novel environment and impaired behavioral habituation to that environment (Fig. 3); (3) increased cocaine-induced locomotion (Fig. 4a); (4) elevated basal extracellular levels of PFC glutamate (Fig. 5; Tables 1, 2); and (5) a blunted capacity of cocaine to elevate PFC extracellular glutamate levels above baseline (Fig. 6a). Collectively, these data indicate that an intra-PFC infusion of AAV-GFP did not influence the abnormal behavioral and PFC glutamate phenotype of Homer1 KO mice.

\section{$A A V$-Homer $1 c$ reverses genotype differences in working memory and sensorimotor function}

The effects of Homerla and Homerlc overexpression in the PFC were assessed on performance in a water version of the radial arm maze by examining the change in latency to correctly navigate the maze, the change in the number of working memory errors committed during maze navigation, and the sensitization of "chaining” behavior (repeated entries into adjacent arms) across maze task acquisition (Fig. $2 a-c$ ). Whereas a genotypic difference was observed for all of these variables in Homerla-infused mice, no difference was observed between WT and KO mice infused with Homer1c (Table 1). Thus, PFC overexpression of Homer1c reversed the deficits in working memory observed in Homer1 KO mice, indicating an active role for PFC Homer1c in this form of cognitive processing.

The effects of overexpression of Homerl isoforms were also assessed on the capacity of a $90 \mathrm{~dB}$ prepulse to inhibit the startle response to a $110 \mathrm{~dB}$ acoustic stimulus. As illustrated in Figure $2 d$, a genotypic difference was observed in Homerla-infused mice, but no difference in prepulse inhibition was observed between WT and KO mice infused with Homer1c (Table 1). Thus, PFC Homer1c actively regulates sensorimotor processing.

\section{AAV-Homer1 a reverses genotypic differences in emotional reactivity}

To assess for the effects of Homerla and Homerlc upregulation after behavioral despair, we used a Porsolt swim test. Mice were subjected to a 15 min forced swim exposure and then examined for differences in floating behavior $24 \mathrm{~h}$ later. There was a marked genotypic difference between Homerlc-infused mice regarding both the latency to first exhibit floating (Fig. $3 a$ ) and the total amount of floating exhibited by the mice (Fig. $3 b$ ). In contrast to the data for the radial arm maze and prepulse inhibition above, no genotypic difference was apparent for either variable for mice infused with Homerla (Table 1).

Because Homerla and Homer1c infusion appeared to produce opposite effects after behavioral despair, we further assessed the effects of AAV infusion after emotional reactivity by measuring locomotor hyperactivity in response to a novel environment. As illustrated in Figure $3 c$, both AAVs reversed the genotypic difference in the amount of novelty-induced locomotion expressed by the mice (Table 1). To assess for the effects of AAV infusion after the habituation of locomotor reactivity, we continued to assess the locomotor responsiveness of mice during four additional $30 \mathrm{~min}$ exposures to the locomotor activity chamber environment (Fig. $3 d$ ). In contrast to their similar effect on initial locomotor reactivity, only Homerla infusion reversed the genotypic difference in locomotor habituation across repeated testing (Table 1), whereas Homer1c infusion appeared to enhance the size of the genotypic difference (Fig. 3d). Collectively, these data for emotional reactivity indicate that both Homerla and Homer1c isoforms in the PFC regulate emotional reactivity to novelty, but only Homerla plays an active role in the habituation of emotional responding. Moreover, these data provide novel support for a possible facilitatory role for Homer1c in certain forms of emotional reactivity.

\section{$A A V$-Homer 1 c reverses genotypic differences in sensitivity} to cocaine

In rats, an intra-accumbens infusion of AAV-Homer1c, but not AAV-Homer la, reverses the sensitization of locomotor hyperactivity produced by cocaine, implicating an active role for Homer1c in regulating behavioral sensitivity to this stimulant (Szumlinski et al., 2005c). To examine the role for PFC Homerla and Homer1c expression in regulating the "presensitized" cocaine behavioral phenotype of Homer1 KO mice (Szumlinski et 

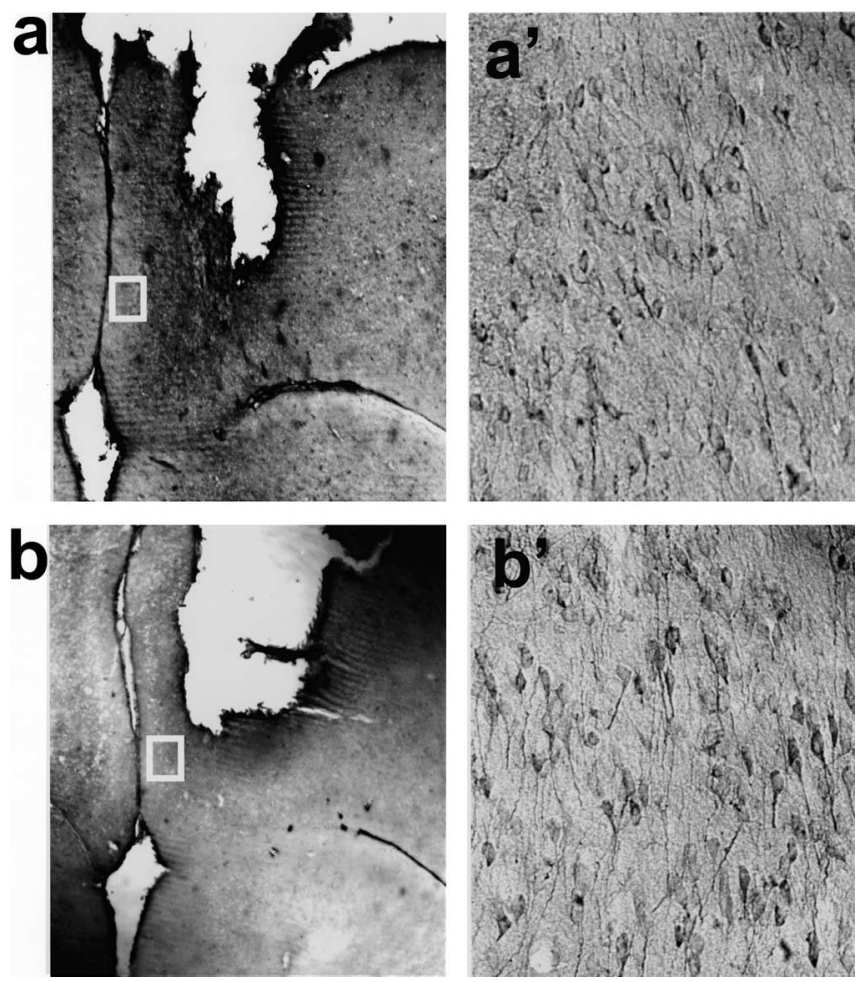

Figure 1. Cellular transfection of the PFC by AAV. Representative immunostaining for the HA tag at 8 weeks after AAV-Homer1a (a) and AAV-Homer1c (b) infusion into the PFC and 3-4d after in vivo microdialysis procedures. $\boldsymbol{a}^{\prime}, \boldsymbol{b}^{\prime}$, High-power $(20 \times)$ micrograph showing cellular transfection within $1.5 \mathrm{~mm}$ of the injection/probe site. Staining was primarily localized to the cell membrane and processes of pyramidal neurons.

al. 2004), we next assessed the effects of intra-PFC AAV infusion after cocaine-induced locomotion (0, 3, 10, and $30 \mathrm{mg} / \mathrm{kg}$, i.p.). Whereas a genotypic difference in cocaine-induced locomotion was apparent in Homerla mice (Fig. 4b), no difference in the dose-response function for cocaine-induced locomotion was observed between Homer1c WT and KO mice (Fig. 4c) (Table 1). Thus, consistent with our recent data for cocaine-sensitized rats (Szumlinski et al., 2005c), Homer1c isoforms actively regulate the behavioral-activating effects of cocaine in mice that are genetically "presensitized."

Interestingly, the effect of AAV infusion after the locomotor response to saline $(0 \mathrm{mg} / \mathrm{kg}$ cocaine) was opposite that observed for cocaine. Consistent with the data for locomotor habituation (Fig. $3 d$ ), Homerla infusion reversed the genotypic difference in the locomotor response to saline ( $0 \mathrm{mg} / \mathrm{kg}$ cocaine) (Fig. $4 b)$, whereas Homer1c infusion was without effect (Fig. 4c). Because these mice have been exposed repeatedly to the activity chambers before conducting this dose-response study, these data lend additional support for an active role for Homer1a in regulating the expression of emotional reactivity in a familiar environment.

\section{$A A V$-Homer1c reverses genotypic differences in PFC} glutamate content

In the cocaine sensitization model of schizophrenia in rats, Homer1c overexpression reverses the decline in basal extracellular levels of glutamate in the accumbens (Szumlinski et al., 2005c). Because the cocaine presensitized behavioral phenotype of Homer1 KO mice is associated with an elevation in PFC levels of glutamate (Szumlinski et al., 2005a), we assessed the effects of AAV infusion after basal extracellular glutamate content and glutamate clearance using the no net-flux in vivo microdialysis tech-
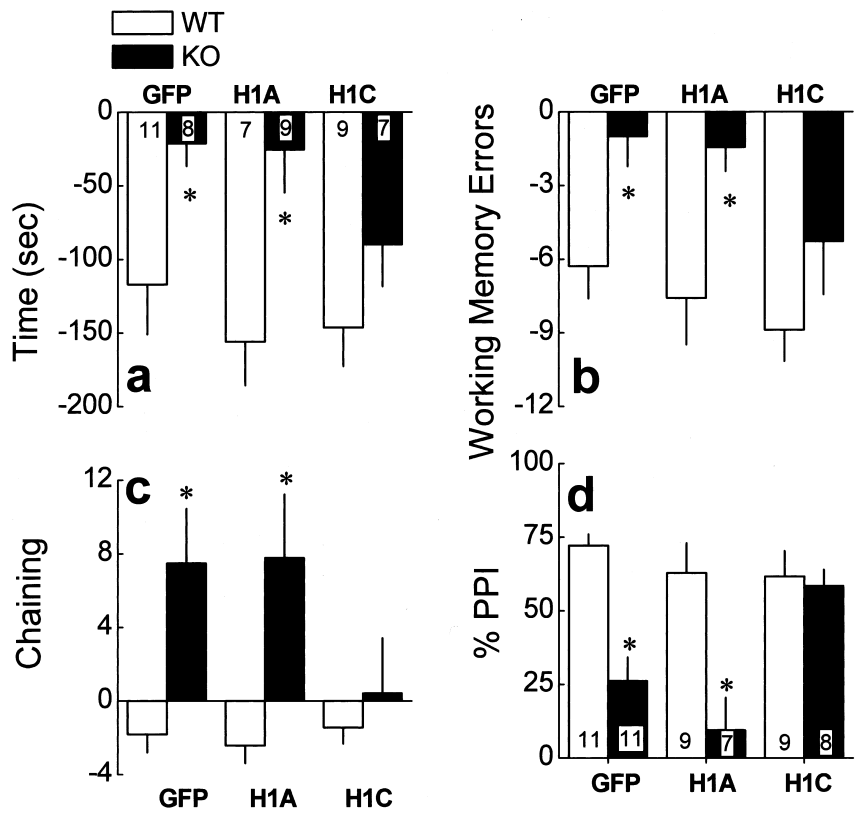

Figure 2. Intra-PFC AAV-Homer1c selectively reverses the genotypic differences in working memory and sensorimotor gating. $\boldsymbol{a}$, Genotypic differences in the reduction in the amount of time taken to locate all four platforms in a radial arm maze task over $14 \mathrm{~d}$ of training were observed in mice infused intra-PFC with AAV-GFP (GFP) or AAV-Homer1a (H1A) but not in mice infused with AAV-Homer1c (H1C). $\boldsymbol{b}$, Similarly, the genotypic difference in the reduction in the number of working memory errors committed during acquisition of the radial arm maze was reversed by AAV-Homer1c. $c$, Genotypic differences in the sensitization of chaining behavior was also reversed by AAV-Homer1c infusion. Data for $\boldsymbol{a}$ - $\boldsymbol{c}$ represent the mean difference between sessions 2 and 14 of radial arm maze acquisition \pm SEM of the number of animals indicated in $\boldsymbol{a}$. $\boldsymbol{d}$, The genotypic difference in PPI was reversed selectively by AAV-Homer1c infusion. Data in $\boldsymbol{d}$ represent the mean percentage inhibition by the $94 \mathrm{~dB}$ prepulse stimulus of the startle elicited by a $110 \mathrm{~dB}$ tone \pm SEM of the number of animals indicated in $\boldsymbol{d}$. ${ }^{*} p<0.05$ versus respective WT (a priori comparisons using univariate ANOVAs).

nique (Table 2). As illustrated in Figure 5, Homer1c selectively reversed the elevation in PFC basal glutamate content produced by Homer 1 deletion, whereas Homerla was without effect (Table 1). Consistent with our previous findings (Szumlinski et al., 2005a), statistical analyses revealed no effect of either gene deletion or AAV infusion on the slopes of the linear regressions in the present study, indicating no effect of manipulating Homer levels on glutamate clearance in the PFC (Table 2). Thus, the Homer 1c isoform plays an active role in regulating basal glutamate content in the PFC without affecting glutamate clearance.

Differential effects of $A A V$-Homerla and $A A V$-Homer1c infusion on the PFC glutamate response to cocaine

The cocaine "presensitized" behavioral phenotype of Homer $1 \mathrm{KO}$ mice is associated also with a blunted capacity of cocaine to elevate extracellular glutamate in the PFC, implicating a role for Homer isoforms in cocaine-induced glutamate release in this brain region (Szumlinski et al., 2005a). Because Homer1c overexpression reversed the effects of Homerl deletion on both sensitivity to the locomotor effects of cocaine (Fig. $4 c$ ) and PFC basal glutamate content (Fig. 5), the effects of AAV infusion on the glutamate response to cocaine in the PFC were assessed using conventional in vivo microdialysis techniques. Consistent with the results of the no net-flux study, Homer1c infusion, but not Homerla infusion, reversed the genotypic difference in basal extracellular glutamate (Table 2). Interestingly, cocaine failed to elevate PFC glutamate in either genotype infused with Homerla (Fig. 6b). In contrast, cocaine elicited a rise in extracellular gluta- 
mate in Homer1c-KO mice and appeared to enhance the glutamate response to cocaine in their WT counterparts (Fig. $6 c$ ). Collectively, these data indicate that the Homerlc isoform actively regulates cocaine-stimulated glutamate release in the PFC and that Homerla overexpression may inhibit evoked glutamate release in this brain region.

\section{Discussion}

Extensive behavioral and neurochemical phenotyping of Homer 1 $\mathrm{KO}$ mice provided face, predictive, and construct validation of this mouse as a potential genetic animal model of schizophrenia (Szumlinski et al., 2004, 2005a). In mammals, alternative transcription of Homerl yields both IEG and constitutively expressed gene products (Brakeman et al., 1997; Kato et al., 1998; Bottai et al., 2002). Using AAVs to distinguish between the IEG Homer1 isoform Homerla and the constitutively expressed (CC) Homer1 isoform Homer 1c, we found that PFC Homerla overexpression selectively reversed genotypic differences observed for behavioral reactivity in paradigms involving repeated exposure to stressful stimuli. Conversely, Homerlc overexpression selectively reversed genotypic differences in working memory and sensorimotor processing, sensitivity to cocaine, and basal PFC glutamate content. Although, Homerla overexpression failed to alter basal glutamate content, it prevented the cocaineinduced rise in PFC extracellular glutamate, whereas Homer 1c overexpression facilitated cocaine-stimulated glutamate levels in $\mathrm{KO}$ mice and enhanced the increase in glutamate in WT animals. Collectively, these data indicate active and dissociable roles for both Homerla and Homerlc in regulating excitatory neurotransmission within the PFC and demonstrate the importance of their relative expression in mediating normal cognitive, sensorimotor, and emotional processing as well as sensitivity to the psychomotor-activating effects of stimulant drugs.

\section{Homer1c in cognitive and sensorimotor processing}

Despite our understanding of the role for Homer1 isoforms in regulating neuronal morphology and cellular function (for reviews, see Xiao et al., 2000; Fagni et al., 2002; de Bartolomeis and Iasevoli, 2003), only recently have we begun to understand the role for Homer proteins in behavior. IEG Homer1 isoforms are induced in several limbo-corticostriatal structures by environmental stress/novelty (Vazdarjanova et al., 2002), footshock (Igaz et al., 2004), psychotomimetic drugs (Brakeman et al., 1997; Cochran et al., 2002; Nichols and Sanders-Bush, 2002; Fujiyama et al., 2003) and antipsychotic medications (de Bartolomeis et al., 2002; Polese et al., 2002), whereas Homer $1 \mathrm{~b} / \mathrm{c}$ is downregulated in striatal structures by withdrawal from repeated cocaine (Swanson et al., 2001). These correlative data suggested an important role for the interplay between Homer1 isoforms in regulating behavior, in particular drug-induced changes in behavior. In support of this notion, Homer1 deletion or the intra-accumbens infusion of antisense oligonucleotides against Homerl increases sensitivity to the acute psychomotor-activating effects of stimulants or dissociative anesthetics (Ghasemzadeh et al., 2003; Szumlinski et al., 2004, ANOVA). COC, Cocaine.

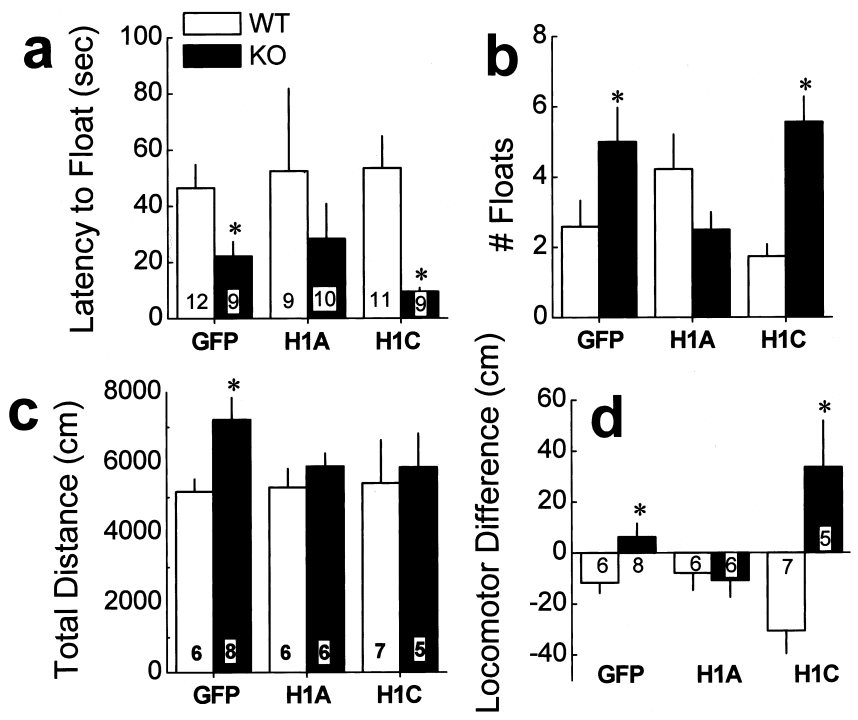

Figure 3. Intra-PFC AAV-Homer1a selectively reverses the genotypic differences in stressrelated learning. $\boldsymbol{a}$, The genotypic difference in the latency to first exhibit floating on a Porsolt swim test conducted $24 \mathrm{~h}$ after forced swim exposure was reversed only by AAV-Homer $1 \mathrm{a}(\mathrm{H} 1 \mathrm{~A})$ infusion. $\boldsymbol{b}$, Similarly, AAV-Homer1a infusion reversed the genotypic difference in the number of floating events exhibited by the mice. $c$, The genotypic difference in the locomotor hyperactivity of mice exposed to a novel activity monitor was reversed by both intra-PFC AAV-Homer1a and AAV-Homer1c (H1C) infusion. $\boldsymbol{d}$, The genotypic difference in locomotor habituation produced by five daily exposures to the locomotor activity chambers was reversed selectively by AAV-Homer1a infusion. Data represent the difference in the total distance traveled in $30 \mathrm{~min}$ from the first and fifth exposure session. The data represent the mean \pm SEM of the number of animals indicated. ${ }^{*} p<0.05$ versus respective WT (a priori comparisons using a univariate ANOVA).
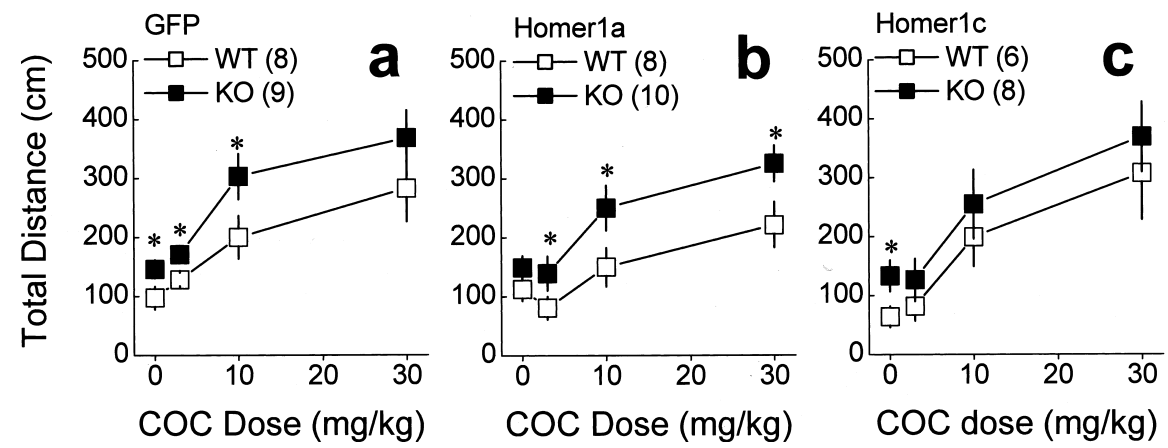

Figure 4. Differential effects of intra-PFCAAV-Homer1a and AAV-Homer1c on the locomotor response to saline and cocaine. $\boldsymbol{a}$ Genotypic differences in the amount of saline- and cocaine-induced locomotion were observed between AAV-GFP (GFP) mice. $\boldsymbol{b}$, Although intra-PFC infusion of AAV-Homer1a reversed the genotypic difference in locomotion induced by saline, it did not influence that induced by cocaine. $c$, In contrast, AAV-Homer1c reversed the genotypic difference in the locomotor response to cocaine but not that to saline. Data represent the mean total distance (in centimeters) traveled by the mice during 60 min sessions \pm SEM of the number of animals indicated. ${ }^{*} p<0.05$ versus respective WT (a priori comparisons using a univariate

2005a). Recent attempts to delineate the relative roles for IEG versus CC-Homer1 isoforms in behavior have indicated an important role for CC isoforms. Whereas an intrahippocampal infusion of AAV-Homerla disrupts Morris water maze performance in wild-type rats, AAV-Homer1c infusion facilitates performance on this task (Klugmann et al., 2005). In conjunction with our virus reversal data for radial arm maze performance (Fig. 2), these data suggest a necessary and facilitatory role for the Homer1c isoform in mediating neural plasticity within cortical structures associated with normal learning and memory processes. Because AAV-Homer1c infusion selec- 


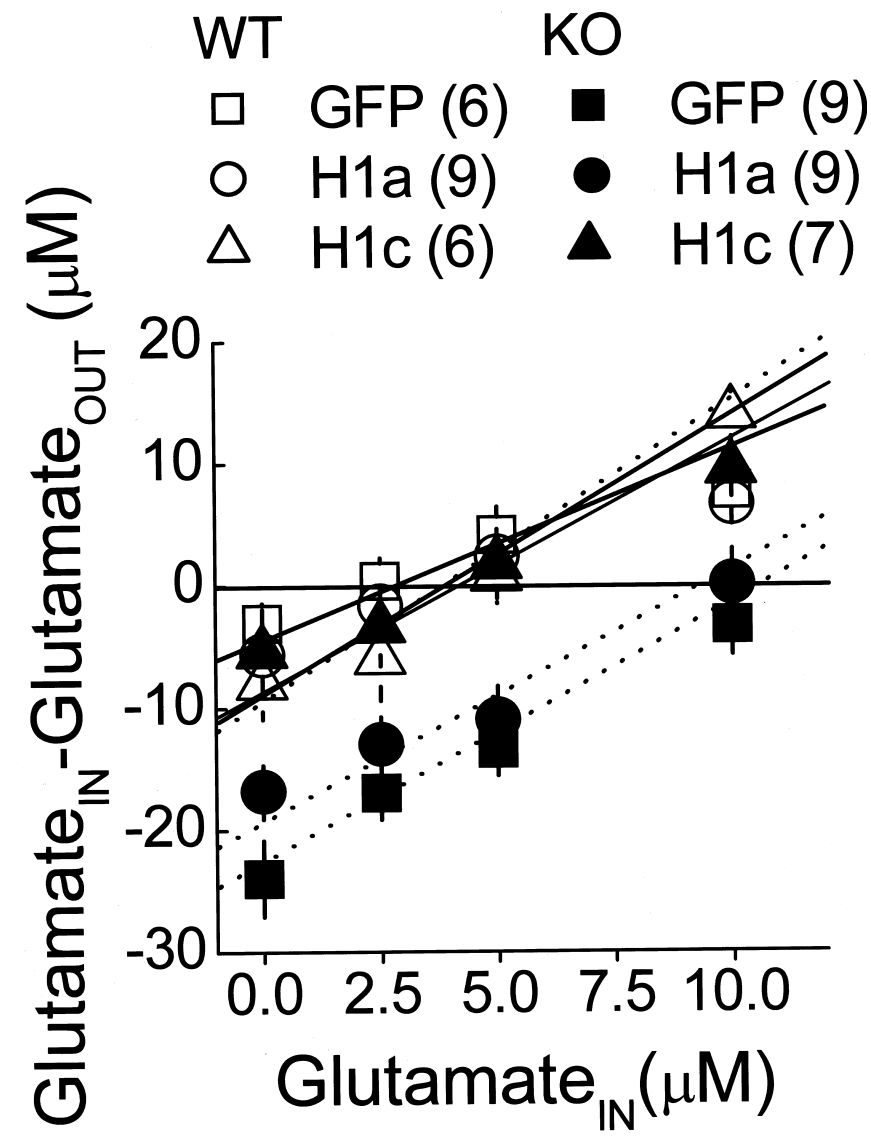

Figure 5. Intra-PFC AAV-Homer1c selectively reverses the genotypic differences in basal extracellular glutamate content in the PFC. The genotypic difference in PFC basal extracellular glutamate content ( $y=0$ ) was reversed selectively by intra-PFC AAV-Homer1c $(\mathrm{H} 1 \mathrm{c})$ infusion when assessed by no net-flux in vivo microdialysis. Data represent the mean dialysate glutamate concentration of two 20 min samples for each concentration \pm SEM of the number of animals indicated.

tively reversed the sensorimotor gating deficits noted for $\mathrm{KO}$ mice, it is suggested that an improvement in attentional processing by restoration of Homer1c expression in the PFC of $\mathrm{KO}$ mice may also have contributed to the observed rescue of radial arm maze performance.

\section{Homerla and coping with stress}

Whereas AAV-Homerla infusion into the PFC did not influence radial arm maze performance or prepulse inhibition of acoustic startle, AAV-Homerla selectively reversed the effects of Homer 1 deletion on swimming behavior in a Porsolt swim test, locomotor habituation, and the locomotor response to a saline injection. It is noteworthy that all of the paradigms in which AAV-Homerla was selective in its reversal of the $\mathrm{KO}$ phenotype involved the retention of information regarding a stressful or aversive event and its subsequent recall within a $24 \mathrm{~h}$ period. IEG Homer1 isoforms are upregulated in cortical structures, including the frontal cortex, by exposure to novel environments (Vazdarjanova et al., 2002) and by the administration of psychotomimetic drugs (Brakeman et al., 1997; Cochran et al., 2002; Nichols and Sanders-Bush, 2002; Fujiyama et al., 2003). More recently, an upregulation of Homerla was observed in the hippocampus at $24 \mathrm{~h}$ after a one-trial avoidance learning task, indicating that this IEG exhibits a protracted profile of expression that may impact responding to a subsequent aversive event (Igaz et al., 2004).
Table 2. Summary of the points of no net-flux ( $y=0$; estimate of extracellular glutamate content) and the slopes of the linear regression analyses (estimate of glutamate clearance) derived from the no net-flux microdialysis study in WT and KO mice infused intra-PFC with AAVs carrying GFP, Homer1a, or Homer1c

\begin{tabular}{lcccc}
\hline AAV & Genotype $(n)$ & $y=0(\mu \mathrm{m})$ & Slope & $\begin{array}{l}\text { Glutamate } \\
(\mathrm{pmol})\end{array}$ \\
\hline GFP & WT (6) & $2.92 \pm 0.48$ & $1.06 \pm 0.08$ & $82.4 \pm 16.3$ \\
& KO (9) & $10.81 \pm 2.61^{*}$ & $1.43 \pm 0.38$ & $135.8 \pm 14.8^{*}$ \\
Homer1a & WT (9) & $4.16 \pm 1.05$ & $1.19 \pm 0.11$ & $94.0 \pm 17.1$ \\
& KO (9) & $9.55 \pm 2.51^{*}$ & $1.28 \pm 0.17$ & $154.2 \pm 19.6^{*}$ \\
Homer1c & WT (6) & $4.84 \pm 1.40$ & $1.47 \pm 0.20$ & $74.3 \pm 22.3$ \\
& KO (7) & $3.87 \pm 0.73$ & $2.18 \pm 0.61$ & $45.4 \pm 11.5$
\end{tabular}

Extracellular glutamate levels derived from conventional microdialysis techniques revealed a similar interaction between genotype and AAV pretreatment. ${ }^{*} p<0.05$ versus respective WT (a priori comparisons). Sample sizes are indicated in parentheses.

Together, these data implicate mutations affecting the induction of IEG Homer1 transcriptional variants as a genetic determinant of vulnerability to stress. Moreover, it is suggested from these data that the induction of Homerla in cortical and allocortical structures is a necessary cellular response to stress that may enable an organism to make an adaptive behavioral response in the short term.

Homer isoforms, PFC glutamate, and schizophrenia

A dysfunction in limbo-corticostriatal glutamate is implicated in the pathophysiology of schizophrenia, a neuropsychiatric condition characterized by abnormalities in cognitive, motivational, sensorimotor, and emotional processing (Lewis and Lieberman, 2000; Tsai and Coyle, 2002; Krystal et al., 2003). In humans, Homer1 (5q14.2) is localized to chromosome 5 (Xiao et al., 1998), and a number of linkage studies indicate susceptibility loci on this chromosome in individuals affected with schizophrenia or schizoaffective disorder (Levinson et al., 2000; Gurling et al., 2001; Paunio et al., 2001). A IVS4 + A>G substitution in intron 4 of Homer 1 has been associated with schizophrenia in a large but very heterogeneous population (Norton et al., 2003). The N-terminal EVH1 domain of Homer1 is encoded by exons $1-5$, whereas the leucine zipper/CCdomain is encoded by exons 6-10 (Bottai et al., 2002; Norton et al., 2003). A large central intron 5 separates these two encoding regions and contains the sequences involved in the activity-dependent premature termination of Homer 1 transcription (Bottai et al., 2002). Thus, if substantiated by further linkage analyses, a Homer1 IVS4 $+\mathrm{A}>\mathrm{G}$ substitution would be expected to impact both IEG and CC-Homer1 transcription, thereby implicating both IEG and CC-Homer1 isoforms in the pathophysiology of schizophrenia.

Deletion of Homer1, but not of Homer2, produces abnormalities in PFC glutamate that are hypothesized to underlie the selective detrimental effect of Homer1 deletion on cognitive, sensorimotor, emotional, and motivational processing (Szumlinski et al., 2004, 2005a). In support of this link between PFC glutamate and behavior, amelioration of the working memory and sensorimotor deficits of $\mathrm{KO}$ mice by $\mathrm{PFC}$ Homer 1c overexpression were accompanied by a reduction in basal extracellular glutamate content and a facilitation of stimulated glutamate release. Thus, by restoring normal (WTtype) glutamate tone within the PFC, Homer1c may reduce the autoinhibition of glutamatergic transmission, thus enabling the gating of relevant sensory information and facilitating attentional processes required for complex learning tasks. 
Because PFC Homerla expression did not influence the phenotype of $\mathrm{KO}$ mice along variables associated with working memory, sensorimotor function or PFC glutamate implicates mutations affecting the transcription of CC-Homer 1 isoforms or the ability of CC-Homers to multimerize, rather than mutations affecting EVH1 binding, in the manifestation of dysregulated excitatory transmission within the PFC underlying cognitive and sensorimotor gating dysfunction.

Mutational analyses have associated a mutation in GRM5 with schizophrenia (Devon et al., 2001), and mice with deletions of either mGluR1 or mGluR5 exhibit prepulse inhibition deficits akin to Homer1 KO mice (Brody et al., 2003, 2004). In rodent models, antagonists at mGluR5 potentiate the deficits in prepulse inhibition produced by NMDA receptor blockade (Henry et al., 2002; Pietraszek et al., 2005), whereas group $1 \mathrm{mGluR}$ agonists can reverse these deficits (Maeda et al., 2003). Because deletion of genes encoding CCHomers downregulates group $1 \mathrm{mGluR}$ function in all cortical areas (Szumlinski et al., 2004) and group1 mGluRs regulate extracellular levels of glutamate in the PFC (Melendez et al., 2005), it is suggested further that the formation of CC-Homer-group1 mGluR signaling complexes may be essential for maintaining basal extracellular glutamate levels in the PFC and for regulating glutamate release during attentional or cognitive tasks.

\section{CC-Homers and cocaine-induced neural plasticity}

Epidemiological studies have revealed a high degree of comorbidity between schizophrenia and psychomotor stimulant abuse disorders (Batel, 2000; Gerber and Tonegawa, 2004). Consistent with this, Homer1 KO mice exhibit increased sensitivity to both the locomotor-activating and the conditioned rewarding effects of cocaine (Szumlinski et al., 2004). In support of a more critical role for CC-Homer isoforms in the regulation of behavioral sensitivity to cocaine, deletion of Homer2, a gene with no known IEG transcriptional variants, also enhances cocaine behavioral and neurochemical sensitivity, which is reversed by an intra-accumbens infusion of AAVHomer2b (Szumlinski et al., 2004). Moreover, an intraaccumbens infusion of a TAT-Homer2a fusion protein or AAVs carrying Homer1c and Homer2b, but not Homer1a, completely prevented the expression of cocaine-induced behavioral and glutamate sensitization in rats (Szumlinski et al., 2005c). The present results extend these data to the PFC and indicate an inhibitory role for corticoaccumbens CC-Homer1 isoforms in sensitivity to psychostimulants. PFC Homer1c expression also facilitated the capacity of cocaine to enhance extracellular glutamate in the PFC, a finding consistent with neuroimaging evidence demonstrating an inhibitory role for frontal cortical structures, in particular the orbitofrontal cortex, in gating behavioral responses to cocaine and cocaineassociated stimuli (Goldstein and Volkow, 2002). Thus, it may be proposed that by maintaining glutamate tone in the frontal cortex, Homer1c also enables cortical activation inhibiting addiction-related behaviors.

\section{Conclusions}

Through an examination of the effects of restoring Homerla and Homer1c expression to the PFC of Homer1 KO mice, the present study implicates a distinct and active role for the Homerla isoform in regulating the ability to cope with repeated stress and for the Homer1c isoform in the regulation of basal and stimulated glutamate release in the PFC mediating attentional and cognitive processing. Although the cellular mechanisms underlying the distinctions between Homerla and Homer1c isoforms in regulating behavior associated with corticoaccumbens glutamate transmission are not defined in the present study, these data support Homer1 polymorphisms affecting the transcription of IEG and CC-Homer1 isoforms in the etiology of schizophrenia, as well as stimulant abuse comorbidity. Moreover, these data implicate Homer-associated intracellular signaling mechanisms as potential targets for the development of novel pharmacotherapeutics for the treatment of these disorders.

\section{References}

Abe H, Misaka T, Tateyama M, Kubo Y (2003) Effects of coexpression with Homer isoforms on the function metabotropic glutamate receptor 1alpha. Mol Cell Neurosci 23:157-168.

Ango F, Prezeau L, Muller T, Tu JC, Xiao B, Worley PF, Pin JP, Bockaert J, Fagni L (2001) Agonist-independent activation of metabotropic glutamate receptors by the intracellular protein Homer. Nature 411:962-965.

Batel P (2000) Addiction and schizophrenia. Eur Psychiatry 15:115-122.

Bottai D, Guzowski JF, Schwarz MK, Kang SH, Xiao B, Lanahan A, Worley PF, Seeburg PH (2002) Synaptic activity-induced conversion or intronic to exonic sequence in Homer 1 immediate early gene expression. J Neurosci 22:167-175.

Brakeman PR, Lanahan AA, O’Brien R, Roche K, Barnes CA, Huganir RL, Worley PF (1997) Homer: a protein that selectively binds metabotropic glutamate receptors. Nature 386:221-223.

Brody SA, Conquet F, Geyer MA (2003) Disruption of prepulse inhibition in mice lacking mGluR1. Eur J Neurosci 18:3361-3366.

Brody SA, Dulawa SC, Conquet F, Geyer MA (2004) Assessment of a prepulse inhibition deficit in a mutant mouse lacking mGlu5 receptors. Mol Psychiatry 9:35-41.

Clark KR, Liu X, McGrath JP, Johnson PR (1999) Highly purified recombinant adeno-associated virus vectors are biologically active and free of detectable helper and wild-type viruses. Hum Gene Ther 10:1031-1039.

Cochran SM, Fujimura M, Morris BJ, Pratt JA (2002) Acute and delayed effects of phencyclidine upon mRNA levels of markers of glutamatergic 
and GABAergic neurotransmitter function in the rat brain. Synapse 46:206-214.

de Bartolomeis A, Iasevoli F (2003) The Homer family and the signal transduction system at glutamatergic postsynaptic density: potential role in behavior and pharmacotherapy. Psychopharmacol Bull 37:51-83.

de Bartolomeis A, Aloj L, Ambesi-Impiombato A, Bravi D, Curaco C, Muscettola G, Barone P (2002) Acute administration of antipsychotics modulates Homer striatal gene expression differentially. Brain Res Mol Brain Res 98:124-129.

Devon RS, Anderson S, Teague PW, Muir WJ, Murray V, Pelosi AJ, Blackwood DH, Porteus DJ (2001) The genomic organisation of the metabotropic glutamate receptor subtype 5 gene, and its association with schizophrenia. Mol Psychiatry 6:311-314.

During MJ, Young D, Baer K, Lawlor P, Klugmann M (2003) Development and optimization of adeno-associated virus vector transfer into the central nervous system. Methods Mol Med 76:221-236.

Fagni L, Worley PF, Ango F (2002) Homer as both a scaffold and transduction molecule. Sci STKE 2002:RE8.

Feng W, Tu J, Yang T, Vernon PS, Allen PD, Worley PF, Pessah IN (2002) Homer regulates gain of ryanodine receptor type 1 channel complex. J Biol Chem 277:44722-44730.

Fujiyama K, Kajii Y, Hiraoka S, Nishikawa T (2003) Differential regulation by stimulants of neocortical expression of mrtl, arc, and homerla mRNA in the rats treated with repeated methamphetamine. Synapse 49:143-149.

Gerber DJ, Tonegawa S (2004) Psychotomimetic effects of drugs-a common pathway to schizophrenia? N Engl J Med 350:1047-1048.

Ghasemzadeh MB, Permenter LK, Lake R, Worley PF, Kalivas PW (2003) Homer 1 proteins and AMPA receptors modulate cocaine-induced behavioural plasticity. Eur J Neurosci 18:1645-1651.

Glass GV, Hopkins KD (1984) Statistical methods in education and psychology, Ed 2, pp 383-384. Englewood Cliffs, NJ: Prentice-Hall.

Goldstein RZ, Volkow ND (2002) Drug addiction and its underlying neurobiological basis: neuroimaging evidence for the involvement of the frontal cortex. Am J Psychiatry 159:1642-1652.

Gurling HM, Kalsi G, Brynjolfson J, Sigmundsson T, Sherrington R, Mankoo BS, Read T, Murphy P, Blaveri E, McQuillin A, Petursson H, Curtis D (2001) Genomewide genetic linkage analysis confirms the presence of susceptibility loci for schizophrenia, on chromosomes 1q32.2, 5q33.2, and 8p21-22 and provides support for linkage to schizophrenia, on chromosomes 11q23.3-24 and 20q12.1-11.23. Am J Hum Genet 68:661-673.

Hauck B, Chen L, Xiao W (2003) Generation and characterization of chimeric recombinant AAV vectors. Mol Ther 7:419-425.

Hennou S, Kato A, Schneider EM, Lundstrom K, Gahwiler BH, Inokuchi K, Gerber U, Ehrengruber MU (2003) Homer-1a/Vesl-1S enhances hippocampal synaptic transmission. Eur J Neurosci 18:811-819.

Henry SA, Lehmann-Masten V, Gasparini F, Geyer MA, Markou A (2002) The mGluR5 antagonist MPEP, but not the mGluR2/3 agonist LY314582, augments PCP effects on prepulse inhibition and locomotor activity. Neuropharmacology 43:1199-1209.

Igaz LM, Bekinschtein P, Izquierdo I, Medina JH (2004) One-trial aversive learning induces late changes in hippocampal CaMKIIalpha, Homer 1a, Syntaxin 1a and ERK2 protein levels. Brain Res Mol Brain Res 132:1-12.

Inoue $\mathrm{Y}$, Honkura N, Kato A, Ogawa S, Udo H, Inokuchi K, Sugiyama H (2004) Activity-inducible protein Homerla/Vesl-1S promotes redistribution of postsynaptic protein Homer1c/Vesl-1L in cultured rat hippocampal neurons. Neurosci Lett 354:143-147.

Kammermeier P, Xiao B, Tu J, Worley P, Ikeda S (2000) Homer proteins regulate coupling of group I metabotropic glutamate receptors to N-type calcium and M-type potassium channels. J Neurosci 20:7238-7245.

Kato A, Ozawa F, Saitoh Y, Fukazawa Y, Sugiyama H, Inoduchi K (1998) Novel members of the Vesl/Homer family of PDZ proteins that bind metabotropic glutamate receptors. J Biol Chem 273:23969-23975.

Klugmann M, Wymond Symes C, Leichtlein CB, Klaussner BK, Dunning J, Fong D, Young D, During MJ (2005) AAV-mediated hippocampal expression of short and long Homer 1 proteins differentially affect cognition and seizure activity in adult rats. Mol Cell Neurosci 28:347-360.

Krystal JH, D’Souza DC, Mathalon D, Perry E, Belger A, Hoffman R (2003) NMDA antagonist effects, cortical glutamatergic function, and schizophrenia: toward a paradigm shift in medication development. Psychopharmacology 169:215-233.
Levinson DF, Homans P, Straub RE, Owen M, Wildenauer DB, Gejman PV, Pulver AE, Laurent C, Kendler KS, Walsh D, Norton N, Williams NM, Schwab SG, Lerer B, Mowry BJ, Sanders AR, Antonarakis SE, Blouin JL, DeLeuze JF, Mallet J (2000) Multicenter linkage study of schizophrenia candidate regions on chromosomes $5 \mathrm{q}, 6 \mathrm{q}, 10 \mathrm{p}$, and 13a: schizophrenia linkage collaborative group III. Am J Hum Genet 67:652-663.

Lewis DA, Lieberman JA (2000) Catching up on schizophrenia: natural history and neurobiology. Neuron 28:325-334.

Maeda J, Suhara T, Okauchi T, Semba J (2003) Different roles of group I and group II metabotropic glutamate receptors on phencyclidineinduced dopamine release in the rat prefrontal cortex. Neurosci Lett 336:171-174

Melendez RI, Vuthiganon J, Kalivas PW (2005) Regulation of extracellular glutamate in the prefrontal cortex: focus on the cystine glutamate exchanger and group I metabotropic glutamate receptors. J Pharmacol Exp Ther 314:139-147.

Minami I, Kengaku M, Smitt PS, Shigeomoto R, Hirano T (2003) Longterm potentiation of mGluR 1 activity by depolarization-induced Homerla in mouse cerebellar Purkinje neurons. Eur J Neurosci 17:1023-1032.

Naisbitt S, Kim E, Tu JC, Xiao B, Sala C, Valtschanoff J, Weinberg RJ, Worley PF, Sheng M (1999) Shank, a novel family of postsynaptic density proteins that binds to the NMDA receptor/PSD-95/GKAP complex and cortactin. Neuron 23:569-582.

Nichols CD, Sanders-Bush E (2002) A single dose of lysergic acid diethylamide influences gene expression patterns within the mammalian brain. Neuropsychopharmacology 26:634-642.

Norton N, Williams HJ, Williams NM, Spurlock G, Zammit S, Jones G, Jones S, Owen R, O'Donovan MC, Owen MJ (2003) Mutation screening of the Homer gene family and association analysis in schizophrenia. Am J Med Genet 120B:18-21.

Paunio T, Ekelund J, Varillo T, Parker A, Hovatta I, Turunen JA, Rinard K, Foti A, Terwilliger JD, Juvonen H, Suvisaari J, Arajarvi R, Suokas J, Partonen T, Lonnqvist J, Meyer J, Peltonen L (2001) Genome-wide scan in a nationwide study sample of schizophrenia families in Finland reveals susceptibility loci on chromosomes $2 \mathrm{q}$ and $5 \mathrm{q}$. Hum Mol Genet 10:3037-3048.

Pietraszek M, Gravius A, Schafer D, Weil T, Trifanova D, Danysz W (2005) mGluR5, but not mGluR1, antagonist modifies MK-801-induced locomotor activity and deficit of prepulse inhibition. Neuropharmacology 49:73-85.

Polese D, Amato de Serpis A, Ambesi-Impiombato A, Muscettola G, de Bartolomeis A (2002) Homer la gene expression modulation by antipsychotic drugs: involvement of the glutamate metabotropic system and effects of D-cycloserine. Neuropsychopharmacology 27:906-913.

Rong R, Ahn JY, Huang H, Nagata E, Kalman D, Kapp JA, Tu J, Worley PF, Snyder SH, Ye K (2003) PI3 kinase enhancer-Homer complex couples mGluRI to PI3 kinase, preventing neuronal apoptosis. Nat Neurosci 6:1153-1161.

Sala C, Piech V, Wilson NR, Passafaro M, Liu G, Sheng M (2001) Regulation of dendritic spine morphology and synaptic function by Shank and Homer. Neuron 31:115-130.

Sala C, Futai K, Yamamoto K, Worley PF, Hayashi Y, Sheng M (2003) Inhibition of dendritic spine morphogenesis and synaptic transmission by activity-inducible protein Homerla. J Neurosci 23:6327-6337.

Swanson C, Baker D, Carson D, Worley P, Kalivas PW (2001) Repeated cocaine administration attenuates group I metabotropic glutamate receptor-mediated glutamate release and behavioral activation: a potential role for Homer 1b/c. J Neurosci 21:9043-9052.

Szumlinski KK, Dehoff MH, Kang SH, Frys KA, Lominac KD, Rohrer J, Griffin W III, Klugmann M, Toda S, Champtiaux NP, Berry T, Shealy S, Tu JC, During MJ, Middaugh LD, Worley PF, Kalivas PW (2004) Homer proteins regulate sensitivity to cocaine. Neuron 43:401-413.

Szumlinski KK, Lominac KD, Kleschen M, Oleson EB, Dehoff M, Schwarz M, Seeburg PH, Worley PF, Kalivas PW (2005a) Behavioural and neurochemical phenotyping of Homer 1 mutant mice: Possible implications for schizophrenia. Genes Brain Behav 4:273-288.

Szumlinski KK, Lominac KD, Oleson EB, Walker JK, Mason A, Dehoff MH, Klugmann M, Cagle S, Welt K, During MJ, Worley PF, Middaugh LD, 
Kalivas PW (2005b) Homer2 is necessary for ethanol-induced neuroplasticity. J Neurosci 25:7054-7061.

Szumlinski KK, Abernathy KE, Oleson EB, Klugmann M, Lominac KD, He D-Y, Ron D, During MJ, Kalivas PW (2005c) Homer isoforms differentially regulate cocaine-induced neuroplasticity. Neuropsychopharmacology, in press.

Tsai G, Coyle JT (2002) Glutamatergic mechanisms in schizophrenia. Annu Rev Pharmacol Toxicol 42:165-179.

Tu JC, Xiao B, Naisbitt S, Yuan JP, Petralia RS, Brakeman P, Doan A, Aakalu VK, Lanahan AA, Sheng M, Worley PF (1999) Coupling of mGluR/ Homer and PSD-95 complexes by the Shank family of postsynaptic density proteins. Neuron 23:583-592.

Vazdarjanova A, McNaughton BL, Barnes CA, Worley PF, Guzowski JF
(2002) Experience-dependent coincident expression of the effector immediate-early genes arc and Homer la in hippocampal and neocortical neuronal networks. J Neurosci 22:10067-10071.

Xiao B, Tu JC, Petralia RS, Yuan JP, Doan A, Breder CD, Ruggiero A, Lanahan AA, Wenthold RJ, Worley PF (1998) Homer regulates the association of Group 1 metabotropic glutamate receptors with multivalent complexes of Homer-related, synaptic proteins. Neuron 21:707-716.

Xiao B, Tu JC, Worley PF (2000) Homer: a link between neural activity and glutamate receptor function. Curr Opin Neurobiol 10:370-374.

Yuan JP, Kiselyov K, Shin DM, Chen J, Shcheynikov N, Kang SH, Dehoff MH, Schwarz MK, Seeburg PH, Muallem S, Worley PF (2003) Homer binds TRPC family channels and is required for gating of TRPC1 by IP3 receptors. Cell 114:777-789. 